\title{
Periódicos eletrônicos sobre administração disponíveis no portal de periódicos da Coordenação de Aperfeiçoamento de Pessoal de Nível Superior: uma avaliação
}

\author{
Ana Maria Mattos \\ Bibliotecária da Biblioteca da Escola de Administração da \\ Universidade Federal do Rio Grande do Sul (UFRGS). Doutoranda \\ no Programa de Pós-Graduação em Ciência da Informação da \\ Universidade Federal de Minas Gerais (UFMG). \\ E-mail:ammattos@ea.ufrgs.br \\ Eduardo Wense Dias \\ Professor titular aposentado da Escola de Ciência da Informação da \\ Universidade Federal de Minas Gerais (UFMG). \\ E-mail:edias@eci.ufmg.br
}

\section{Resumo}

Este trabalho analisa o conjunto de periódicos eletrônicos de administração disponíveis no Portal Capes, do ponto de vista dos interesses dos usuários de uma biblioteca universitária especializada no assunto. Empregou-se como método a análise das citações dos periódicos utilizados nas teses de doutorado defendidas no Programa de Pós-Graduação em Administração da Escola de Administração da Universidade Federal do Rio Grande do Sul no período 1999-2007. Observou-se que $25 \%$ dos periódicos citados nas teses não estão disponíveis no Portal e que os periódicos disponíveis apresentam limitações quanto à integralidade da coleção.

\section{Palavras-chave}

Biblioteca universitária. Desenvolvimento de coleções. Análise de citações. Periódicos eletrônicos.

\section{Electronic journals in the field of business administration available in portal of journals of Coordination for the Improvement of Higher Level Personnel}

\begin{abstract}
The objective of this paper is to analyze a set of electronic academic journals referring to Business Administration available at Portal CAPES from the point of view of the users' interest concerning a university library specialized on this subject. The methodology used is an analysis of citations of journals utilized by the theses of PhD presented in the Post-graduation
\end{abstract}

Program in Administration of Escola de Administração da Universidade Federal do Rio Grande do Sul from 1999 to 2007. It is important to note that $25 \%$ of the journals cited in the theses are not available at the Portal. The journals available, however, show some lack as to a whole collection.

Keywords

Academic library. Development of collection. Analyses of citation. E-journals.

\section{INTRODUÇÃO}

A criação em 2000 do Portal de Periódicos da Coordenação de Aperfeiçoamento de Pessoal de Nível Superior (Capes) - também chamado de Portal, Portal Capes, Portal de periódicos, Portal de periódicos da Capes, Periódicos Capes, entre outras variações - revolucionou o acesso à informação acadêmica e científica das instituições de ensino superior e institutos de pesquisa no Brasil, modernizando, agilizando e equalizando o acesso à pesquisa em periódicos e bases de dados nacionais e internacionais para todas as regiões do território brasileiro.

Apesar de o Portal ser apontado por Correa et al. (2008, p. 141) como “[...] o maior do mundo em capilaridade, perdendo em volume somente para dois portais americanos que reúnem cerca de 15 mil periódicos cada um [possibilitando somente o] acesso local, enquanto o Portal brasileiro atende a todo o país", e de o fenômeno da desintermediação da informação, que proporciona autonomia e independência aos usuários, apresentar-se como uma tendência no atendimento ao público na Biblioteca Setorial da Escola de Administração 
(BSEA) da Universidade Federal do Rio Grande do Sul (UFRGS), recebeu-se no dia a dia solicitações de artigos de periódicos sobre administração impossíveis de serem atendidas via Portal.

Pelo volume de informações que apresenta, o Portal Capes cria grande expectativa nos usuários da administração, mas percebe-se que suas demandas não são atendidas. Os insucessos nas pesquisas recaem sobre os embargos apresentados pelos títulos. Paradoxalmente, encontram-se os artigos indexados nas bases de dados disponíveis no Portal, mas não há como consultá-los.

Define-se embargo como dificuldade, empecilho, impedimento, impossibilidade ou restrição de acesso a textos completos dos periódicos disponíveis no Portal, seja por apresentarem (i) apenas os resumos (abstracts) dos artigos; (ii) uma lacuna de tempo entre a última edição disponível e a última edição publicada da revista científica; ou (iii) pela não cobertura retrospectiva da assinatura dos títulos, promovendo falhas não cobertas pela coleção física localizada na biblioteca, que era mantida com os recursos financeiros redirecionados ao Portal.

Inicialmente, esta dificuldade motivou uma microanálise do problema (FRAGA; MATTOS, 2008), definindo-se como necessário um aprofundamento do estudo que culmina com esta investigação. Pretende-se utilizar, como instrumento de avaliação do Portal, a relação dos títulos das revistas científicas mais citadas na elaboração das teses dos doutorandos do Programa de PósGraduação em Administração (PPGA) da Escola de Administração (EA) da UFRGS e os periódicos sobre administração que se encontram disponíveis no Portal, visando a verificar sua adequação para esses usuários.

Entende-se que as citações oriundas das teses elaboradas pelos doutorandos do PPGA podem ser aproveitadas para verificar a adequação do Portal, pois listas provenientes de estudos de citações podem ser úteis para identificar os periódicos que devem ter avaliação mais acurada pelos bibliotecários familiarizados com as demandas de seus usuários (LINE, 1978). Além disso, a utilização da frequência de citações pode determinar a seleção da coleção-núcleo dos periódicos de uma biblioteca (GARFIELD, 1977), indicando, se for o caso, uma aquisição complementar para o Portal atender de forma adequada a este público, ou mesmo uma reivindicação junto à Capes da compra deste material informacional.

Optou-se pelo estudo das citações utilizadas na elaboração das teses por representarem estudos originais de real contribuição para a especialidade e pelo fato de o material informacional utilizado em sua elaboração apresentar o que há de mais atual sobre o assunto abordado. Justifica-se esta análise porque a partir dos resultados aqui obtidos podese (i) determinar a coleção-núcleo de periódicos para a BSEA e (ii) avaliar, para os doutorandos da BSEA, a adequação, ou não, dos títulos das revistas científicas sobre administração disponíveis no Portal de periódicos da Capes.

Objetiva-se (i) identificar os títulos de periódicos que formam a coleção-núcleo da biblioteca, de acordo com os usuários doutorandos do PPGA, (ii) localizar estes títulos no Portal e também (iii) quantificar seus períodos de embargo, se existirem.

Acredita-se que o resultado da análise aqui proposta possa determinar quais títulos devem formar a coleção núcleo da BSEA e avaliar, do ponto de vista destes usuários, a adequação do Portal sobre o assunto administração.

\section{PERIÓDICOS ELETRÔNICOS}

Passados mais de 300 anos do nascimento do periódico científico impresso, ocorreram problemas práticos na sua viabilização, tais como demora na publicação dos artigos, aumento do custo de aquisição/manutenção das publicações e ineficiência dos instrumentos de busca nestas coleções.

No século XX, o surgimento da informática despontou como alternativa para a publicação dos periódicos científicos tradicionais, pois a utilização da mídia eletrônica oferece rapidez na comunicação, flexibilidade 
no acesso, amplitude no alcance, disponibilidade imediata e barateamento dos custos relativos de aquisição e manutenção (MUELLER, 2000).

A partir de 1985, passaram a ser produzidas e disseminadas bases de dados utilizando a tecnologia do CD-ROM. Antes do CD-ROM, havia a microficha e o disquete que hoje representam exemplares pertencentes à história (LEMOS, 2006). Apesar de a Internet haver sido implantada no meio acadêmico brasileiro em 1989, sua difusão ocorreu somente na década de 90, facilitando "[...] ainda mais o acesso remoto às bases de dados” (CENDÓN, 2000, p. 221).

Na metade da década de 1990, universidades brasileiras, como a UFRGS e a Universidade de São Paulo, passaram a utilizar os periódicos eletrônicos através das bases de dados, a exemplo do Proquest, dedicado à área de administração. Apesar do custo elevado para as instituições, elas mantinham estas bases pois possibilitavam a pesquisa e permitiam a obtenção da cópia do artigo diretamente do CD-ROM.

Com o passar do tempo, outras bases de dados e novos editores foram agregando outras áreas do conhecimento, chegando até o mundo de informação disponível on-line atualmente. A generalização da publicação dos periódicos em mídia eletrônica traz à reflexão as desvantagens e vantagens do "novo" suporte, mas, como acreditam Cruz et al. (2003), as vantagens superam as desvantagens.

Entre as desvantagens, encontram-se o incômodo de ler na tela e o custo de aquisição, manutenção e atualização dos equipamentos para disponibilizar o acesso à revista. Como vantagens, destacam-se a agilidade na comunicação e o acesso, tanto na elaboração quanto na distribuição do periódico, a significativa economia no preço final do formato eletrônico e a utilização de recursos audiovisuais e de hipermídia (CRUZ et al., 2003). Entretanto, de acordo com Lemos (2006), a vantagem de redução nos custos de aquisição do periódico é questionável:

Convém lembrar que os periódicos, em qualquer formato, não se destinam à compra por pessoas físicas. Seus consumidores principais são as bibliotecas. Esse fato talvez haja criado um mecanismo viciado de atribuição de preços, mesmo porque muitas editoras atribuíam preço mais alto para as assinaturas ditas de uso institucional. [...] Infelizmente, nenhuma das iniciativas de edição eletrônica até hoje resultou em economia relevante para as bibliotecas. As editoras que oferecem assinaturas de versões eletrônicas e impressas tendem a vendê-las por um preço de 'pacote', em geral de 10 a 30\% acima do preço da assinatura apenas da versão em papel (LEMOS, 2006).

Lemos (2006) aponta, ainda, outras três desvantagens: (i) a incerteza quanto à permanência do suporte digital, (ii) o alto custo dos procedimentos de seleção, compra e gerenciamento dos serviços de acesso aos periódicos eletrônicos, e (iii), por fim, ao contrário do que acontece com a publicação impressa, o usuário, no caso a biblioteca, não conserva uma coleção mesmo depois de cancelada sua assinatura eletrônica. Ou seja, paga-se pelo uso e não pela posse. Contudo, a presença do periódico eletrônico tornou-se irreversível e precisamos aprender a conviver com sua existência.

A comunidade científica encontrou duas formas de lidar com esta realidade: vem adotando ao longo do tempo a proposta do Open Archvies Initiative (OAI), que define um modelo de interoperabilidade entre bibliotecas e repositórios digitais e possibilita alternativas para a comunicação científica; além disso, tem participado do movimento mundial em favor do acesso livre à informação científica por meio de propostas de ações que possam viabilizar a iniciativa OAI (KURAMOTO, 2006).

\section{PORTAL CAPES}

O acesso da comunidade acadêmica brasileira à produção científica internacional é garantido pelo Ministério da Educação através da Capes, por meio do Programa de Apoio à Aquisição de Periódicos (PAAP), iniciado em 1995. O PAAP tem a finalidade de subsidiar as assinaturas de periódicos para as instituições de ensino superior, que inicialmente eram efetuadas em papel e pelas próprias instituições (BRASIL, 2006). 
Todavia, no final da década de 1990, devido às restrições orçamentárias e ao surgimento das novas tecnologias de informação que afetaram o mercado editorial de periódicos científicos, tornou-se necessário encontrar uma alternativa mais econômica e racional para manter o PAAP. Além disso, a possibilidade de agilidade na distribuição da informação eletrônica a todas as instituições de pesquisa de maneira uniforme, atendendo a todas as unidades da federação brasileira, tornou-se uma grande vantagem. Sugere-se, para aprofundamento do assunto, o interessante relato histórico sobre a criação do Portal escrito por Correa et al. (2008).

Dutra e Lapolli (2004) descrevem que a Associação Nacional de Dirigentes de Instituições Federais de Ensino Superior, o Fórum de Pró-Reitores de Pesquisa e Pós-Graduação e a Comissão Brasileira de Bibliotecas Universitárias definiram estratégias e linhas de ação do PAAP que culminaram com o estabelecimento de um consórcio nacional de acesso a periódicos eletrônicos - o Portal de periódicos da Capes.

Logo, o acesso à informação científica e tecnológica mantido pelo PAAP passa por uma revolução: a coleção de periódicos impressos na forma tradicional dá espaço ao periódico eletrônico. Por causa desta decisão, o pesquisador brasileiro passa a ter acesso ao artigo no mesmo momento, não importando onde ele esteja: no interior de um estado do Nordeste ou em uma grande capital do Sudeste do país.

Em setembro de 2010, o Portal (BRASIL, c2009, [2010]) apresenta 24.058 títulos de periódicos com texto completo e encontra-se consolidado, representando importante fonte de informação para o desenvolvimento das atividades acadêmicas no país.

\section{MATERIAL E MÉTODO}

Cada indivíduo contribui para o conhecimento construindo sobre o que os outros já edificaram. Neste processo, citações são objetos que nos permitem conectar as contribuições que foram publicadas, desde que se utilizem os métodos bibliométricos adequados.
Escolheu-se a análise de citações como método bibliométrico, que agrega os dados pela contagem de frequência de um documento, ou conjunto de documentos, em ordenação linear, sem considerar suas ligações intelectuais, utilizando para tal a estatística descritiva (OKUBO, 1997). Como material para a investigação, foram utilizadas as citações das teses dos doutorandos do PPGA/EA/ UFRGS defendidas de 1999 até 2007.

$\mathrm{Na}$ literatura, são encontrados alguns autores que consideram possível estudar a comunidade usuária pela análise das citações oriundas das teses e dissertações, pois esta análise pode servir como método indireto de estudo do usuário (SMITH, 1981; TARAPANOFF; MIRANDA; ARAÚJO JÚNIOR, 2004; TUÑÓN BRYDGES, 2005; URBANO SALIDO, 2001), dado que este tipo de investigação permite desenvolver estruturas teóricas a respeito da expectativa do uso dos materiais futuros, baseados nos critérios comuns dos materiais já utilizados (KOVACS, 1990).

Especificamente utilizou-se para a análise de citações a Lei de Bradford, que data de 1934 e mede a produtividade dos periódicos, descrevendo a distribuição da literatura periódica em uma área específica. Bradford (1985) procurou verificar a dispersão dos artigos sobre determinado assunto baseando-se no princípio da unidade da ciência, ou seja, todos os assuntos científicos relacionam-se entre si. Dessa forma, quando ocorre a publicação de artigos especializados em algum assunto, estes artigos, ocasionalmente, podem aparecer em periódicos que não são da sua especialidade.

Assim, um núcleo de periódicos especializados apresenta mais artigos sobre determinado assunto do que os que tratam de assuntos correlatos. Este fenômeno permite ordenar os títulos em zonas de produtividade decrescente de documentos, e o número de periódicos de cada zona aumentará à medida que sua utilização diminuir. A Lei de Bradford indica que os periódicos de um assunto, quando arranjados por número de artigos, podem 
ser divididos em aproximadamente três zonas com o mesmo número de artigos. Por exemplo: supondo 1.500 artigos em 210 periódicos sobre dado tema, haverá aproximadamente 500 artigos em cada zona:

$$
\text { c: } \operatorname{cn}: \operatorname{cn} 2: \ldots
$$

Se, por exemplo, $c=10$ e $n=4$, então:

\section{$10: 10 \times 4: 10 \times 42: \ldots$}

ou

$$
10: 40: 160: \ldots
$$

Ou seja, a primeira zona conterá dez títulos de periódicos, a segunda 40 e a terceira 160 , cada uma com 500 artigos.

Os dados empíricos foram obtidos das citações utilizadas, no caso, os títulos dos periódicos, na elaboração das teses defendidas no PPGA/EA/ UFRGS de 1999 até 2007. Destaca-se que 1999 foi o ano em que ocorreram as primeiras defesas de tese no PPGA, já que o curso de doutorado teve início em 1994. Atualmente, o PPGA encontrase estruturado em seis áreas de concentração: Contabilidade e Finanças, Gestão da Tecnologia e da Produção, Marketing, Organizações, Recursos Humanos e Sistemas de Informação e de Apoio à Decisão. Essas áreas foram consideradas na análise.
Estabeleceu-se que, para pertencer ao universo da pesquisa, a tese cujas citações seriam investigadas deveria reunir duas características: haver sido defendida no PPGA/EA/UFRGS de 1999 até 2007 e ter sido orientada por professores pertencentes ao Departamento de Ciências Administrativas (DCA). $\mathrm{O}$ passo seguinte era a consequente consulta ao catálogo on-line (Online Public Access Catalogue $O P A C)$ do SBU, o SABi ${ }^{1}$.

Para proceder à consulta, selecionou-se, no SABi, o material do tipo "teses e dissertações". Logo após, inseriu-se no campo de pesquisa, por meio da pesquisa Commom Comand Language (CCL), a expressão de busca:

\section{WUN=adm01 and WPI $=$ pd and WYR $=1999->2007$}

Ou seja, WUN para produção intelectual do DCA (adm01), WPI para selecionar somente as teses (pd), WYR para delimitar o recorte temporal a ser estudado (1999 -> 2007).

Considerando o tempo necessário para a investigação, a consulta ao catálogo foi realizada em abril de 2008. Foram recuperadas 95 teses, dentre elas, dez não obedeciam aos critérios estabelecidos para esta pesquisa, tendo sido descartadas. A distribuição das 85 teses por ano de defesa e área de concentração pode ser visualizada na tabela 1 .

\section{TABELA 1}

\begin{tabular}{|c|c|c|c|c|c|c|c|c|c|c|c|}
\hline \multirow{2}{*}{ ÁREA DE CONCENTRAÇÃO } & \multicolumn{9}{|c|}{ ANO } & \multirow{2}{*}{ TOTAL } & \multirow{2}{*}{$(\%)$} \\
\hline & 1999 & 2000 & 2001 & 2002 & 2003 & 2004 & 2005 & 2006 & 2007 & & \\
\hline Gestão da Tecnologia e da Produção & 1 & 1 & 2 & 2 & 0 & 4 & 6 & 7 & 0 & 23 & 27,06 \\
\hline Marketing & 1 & 1 & 3 & 1 & 1 & 2 & 4 & 3 & 2 & 18 & 21,18 \\
\hline Sistemas de Informação e de Apoio à Decisão & 2 & 3 & 2 & 0 & 0 & 2 & 3 & 4 & 0 & 16 & 18,82 \\
\hline Organizações & 0 & 1 & 1 & 1 & 2 & 2 & 3 & 3 & 1 & 14 & 16,47 \\
\hline Recursos Humanos & 0 & 2 & 4 & 0 & 0 & 1 & 2 & 0 & 2 & 11 & 12,94 \\
\hline Contabilidade e Finanças & 0 & 0 & 0 & 0 & 0 & 0 & 2 & 1 & 0 & 3 & 3,53 \\
\hline TOTAL & 4 & 8 & 12 & 4 & 3 & 11 & 20 & 18 & 5 & 85 & 100 \\
\hline$(\%)$ & 4,71 & 9,41 & 14,12 & 4,71 & 3,53 & 12,94 & 23,53 & 21,18 & 5,88 & 100 & \\
\hline
\end{tabular}

\section{Teses defendidas por ano e por área de concentração}

Fonte: Elaborada pelos autores

${ }^{1}$ Sistema de Automação de Bibliotecas. Disponível em: http:// sabix.ufrgs.br/ALEPH?415825923. 
Reunidas as informações sobre cada uma das 85 teses, tais como número do sistema no $\mathrm{SABi}$, ano de defesa, área de concentração, frequência de citações, nome do autor, nome do orientador e título, procedeu-se à contabilização das citações para, em seguida, produzir informações mais refinadas. A seguir, criou-se um banco de dados em Excel para tabular os dados com os campos referência completa, idioma, ano e tipologia. Para classificar as referências, foi feita uma lista de possíveis tipologias de acordo com as normas para elaboração de referências da Associação Brasileira de Normas Técnicas (2002), que norteiam a descrição das referências citadas nas teses estudadas.

O preenchimento das informações no banco de dados possibilitou a aplicação de filtros, inclusive para selecionar somente as publicações periódicas no todo, em parte ou em meio eletrônico. Logo após, foram apagadas todas as informações diferentes do título do periódico, tais como autor, data e título do artigo, que constavam no campo referência, obtendo-se desse modo uma lista dos títulos das revistas científicas citadas pelos autores $\mathrm{da}$ teses estudadas. $\mathrm{O}$ banco de dados revelou um conjunto de 5.068 citações de periódicos utilizadas na elaboração das 85 teses, que se encontram distribuídos entre 1.131 títulos (tabela 2).

Uma vez identificados os títulos dos artigos citados na elaboração das teses que fazem parte desta pesquisa, utilizou-se a Lei de Bradford (1985) para determinar a coleção-núcleo de periódicos, dividindo o resultado apurado em três zonas: (i) a primeira zona apresenta os periódicos relevantes para a formação de um acervo sobre o assunto e que receberam 1.686 citações distribuídas em 17 títulos; (ii) na segunda zona encontram-se os periódicos que não são da especialidade, mas possuem conteúdo que abarca o núcleo da literatura e que receberam 1.705 citações distribuídas em 115 títulos; e (iii) a terceira zona apresenta os periódicos que possuem relação remota com a especialidade examinada e receberam 1.677 citações distribuídas em 999 títulos de periódicos.
$\mathrm{Na}$ perspectiva de um equilíbrio entre as seis diferentes áreas de concentração do PPGA, passouse a tabular os periódicos por área, buscando identificar os que se encontram na primeira zona, de acordo com a Lei de Bradford (1985), para comparálas com os resultados da tabela 2.

Iniciou-se pelas três teses da área de contabilidade e finanças em que os autores utilizaram 176 citações dispersas em 55 títulos de periódicos. A primeira zona apresentada na tabela 3 contém três periódicos, que receberam $34,66 \%$ das citações acumuladas.

$\mathrm{Na}$ tabela 4, observa-se que os autores das 23 teses da área de gestão da tecnologia e da produção utilizaram 1.145 citações distribuídas em 339 periódicos. Nesta área de concentração, a primeira zona apresenta 11 periódicos, que receberam $33,80 \%$ das citações acumuladas.

Os autores das 18 teses sobre marketing utilizaram 1.594 citações distribuídas em 328 periódicos. $\mathrm{Na}$ primeira zona dos periódicos da área (tabela 5), encontraram-se quatro periódicos que receberam $33,69 \%$ das citações acumuladas.

A área de recursos humanos apresenta onze teses e, para produzi-las, os autores utilizaram 593 citações distribuídas em 233 títulos de periódicos. A primeira zona, tabela 6 , contém 12 periódicos, que receberam $33,05 \%$ das citações acumuladas.

A tabela 7 apresenta o conjunto das 568 citações de periódicos utilizadas na elaboração das 14 teses da área de organizações, que se encontram dispersas entre 236 títulos. De acordo com a Lei de Bradford (1985), a primeira zona contém 11 periódicos que receberam 32,75\% das citações acumuladas.

Na tabela 8, revela-se o conjunto das 992 citações distribuídas entre 354 títulos de periódicos utilizados na elaboração das 16 teses estudadas da área de Sistemas de Informação e Apoio à Decisão. De acordo com a Lei de Bradford (1985), a primeira zona contém 14 periódicos que receberam 33,97\% das citações acumuladas. 
Periódicos eletrônicos sobre administração disponíveis no portal de periódicos da Coordenação de Aperfeiçoamento de Pessoal...

TABELA 2

Títulos dos periódicos citados nas teses estudadas

\begin{tabular}{|c|c|c|c|c|c|c|c|c|c|}
\hline \multirow{2}{*}{ TÍTULO } & \multicolumn{4}{|c|}{ PERIÓDICO } & \multicolumn{5}{|c|}{ CITAÇÃO } \\
\hline & FREQ. (A) & $(\%)$ & ACUM. & $(\%)$ & FREQ. (B) & (A) $\times(B)$ & $(\%)$ & ACUM. & $(\%)$ \\
\hline Journal of Marketing & 1 & 0,09 & 1 & 0,09 & 325 & 325 & 6,41 & 325 & 6,41 \\
\hline Harvard Business Review & 1 & 0,09 & 2 & 0,18 & 157 & 157 & 3,10 & 482 & 9,51 \\
\hline Journal of Marketing Research & 1 & 0,09 & 3 & 0,27 & 150 & 150 & 2,96 & 632 & 12,47 \\
\hline Academy of Management Review & 1 & 0,09 & 4 & 0,35 & 133 & 133 & 2,62 & 765 & 15,09 \\
\hline Strategic Management Journal & 1 & 0,09 & 5 & 0,44 & 115 & 115 & 2,27 & 880 & 17,36 \\
\hline Administrative Science Revien & 1 & 0,09 & 6 & 0,53 & 114 & 114 & 2,25 & 994 & 19,61 \\
\hline Revista de Administrafão de Empresas & 1 & 0,09 & 7 & 0,62 & 95 & 95 & 1,87 & 1089 & 21,49 \\
\hline MIS Quarterly & 1 & 0,09 & 8 & 0,71 & 93 & 93 & 1,84 & 1182 & 23,32 \\
\hline Journabf thrAcademy of Marketing Science & 1 & 0,09 & 9 & 0,80 & 82 & 82 & 1,62 & 1264 & 24,94 \\
\hline Sloan Management Revien & 1 & 0,09 & 10 & 0,88 & 68 & 68 & 1,34 & 1332 & 26,28 \\
\hline Revista de Administrafão da USP & 1 & 0,09 & 11 & 0,97 & 60 & 60 & 1,18 & 1392 & 27,47 \\
\hline Academy of Management Journal & 1 & 0,09 & 12 & 1,06 & 55 & 55 & 1,09 & 1447 & 28,55 \\
\hline Journal of Conswmer Researcb & 1 & 0,09 & 13 & 1,15 & 53 & 53 & 1,05 & 1500 & 29,60 \\
\hline Management Science & 1 & 0,09 & 14 & 1,24 & 52 & 52 & 1,03 & 1552 & 30,62 \\
\hline California Management Review & 1 & 0,09 & 15 & 1,33 & 47 & 47 & 0,93 & 1599 & 31,55 \\
\hline Journal of Finance & 1 & 0,09 & 16 & 1,41 & 46 & 46 & 0,91 & 1645 & 32,46 \\
\hline Journal of Management Studies & 1 & 0,09 & 17 & 1,50 & 41 & 41 & 0,81 & 1686 & 33,27 \\
\hline SUBTOTAL & & 1,53 & & & & & 33,27 & & \\
\hline Organization Science & 1 & 0,09 & 18 & 1,59 & 40 & 40 & 0,79 & 1726 & 34,06 \\
\hline 2 títulos diferentes ${ }^{2}$ & 2 & 0,18 & 20 & 1,77 & 39 & 78 & 1,54 & 1804 & 35,60 \\
\hline Research Policy & 1 & 0,09 & 21 & 1,86 & 37 & 37 & 0,73 & 1841 & 36,33 \\
\hline 2 títulos diferentes & 2 & 0,18 & 23 & 2,03 & 36 & 72 & 1,42 & 1913 & 37,75 \\
\hline American Economic Review & 1 & 0,09 & 24 & 2,12 & 34 & 34 & 0,67 & 1947 & 38,42 \\
\hline Journal of Financial Economics & 1 & 0,09 & 25 & 2,21 & 33 & 33 & 0,65 & 1980 & 39,07 \\
\hline 2 títulos diferentes & 2 & 0,18 & 27 & 2,39 & 32 & 64 & 1,26 & 2044 & 40,33 \\
\hline 2 títulos diferentes & 2 & 0,18 & 29 & 2,56 & 29 & 58 & 1,14 & 2102 & 41,48 \\
\hline 2 títulos diferentes & 2 & 0,18 & 31 & 2,74 & 28 & 56 & 1,10 & 2158 & 42,58 \\
\hline Psychological Bulletin & 1 & 0,09 & 32 & 2,83 & 27 & 27 & 0,53 & 2185 & 43,11 \\
\hline 2 titulos diferentes & 2 & 0,18 & 34 & 3,01 & 25 & 50 & 0,99 & 2235 & 44,10 \\
\hline Long Range Planning & 1 & 0,09 & 35 & 3,09 & 24 & 24 & 0,47 & 2259 & 44,57 \\
\hline Revista de Administração Pública & 1 & 0,09 & 36 & 3,18 & 23 & 23 & 0,45 & 2282 & 45,03 \\
\hline 6 titulos diferentes & 6 & 0,53 & 42 & 3,71 & 22 & 132 & 2,61 & 2414 & 47,63 \\
\hline 2 títulos diferentes & 2 & 0,18 & 44 & 3,89 & 20 & 40 & 0,79 & 2454 & 48,42 \\
\hline 4 títulos diferentes & 4 & 0,35 & 48 & 4,24 & 19 & 76 & 1,50 & 2530 & 49,92 \\
\hline 2 titulos diferentes & 2 & 0,18 & 50 & 4,42 & 18 & 36 & 0,71 & 2566 & 50,63 \\
\hline 3 títulos diferentes & 3 & 0,27 & 53 & 4,69 & 17 & 51 & 1,01 & 2617 & 51,64 \\
\hline Revista Brasileira de Saúde Ocupacional & 1 & 0,09 & 54 & 4,77 & 16 & 16 & 0,32 & 2633 & 51,95 \\
\hline 3 titulos diferentes & 3 & 0,27 & 57 & 5,04 & 15 & 45 & 0,89 & 2678 & 52,84 \\
\hline 3 títulos diferentes & 3 & 0,27 & 60 & 5,31 & 14 & 42 & 0,83 & 2720 & 53,67 \\
\hline 9 títulos diferentes & 9 & 0,79 & 69 & 6,10 & 13 & 117 & 2,31 & 2837 & 55,98 \\
\hline 7 títulos diferentes & 7 & 0,62 & 76 & 6,72 & 12 & 84 & 1,66 & 2921 & 57,64 \\
\hline 6 títulos diferentes & 6 & 0,53 & 82 & 7,25 & 11 & 66 & 1,30 & 2987 & 58,94 \\
\hline 8 títulos diferentes & 8 & 0,71 & 90 & 7,96 & 10 & 80 & 1,58 & 3067 & 60,52 \\
\hline 8 títulos diferentes & 8 & 0,71 & 98 & 8,66 & 9 & 72 & 1,42 & 3139 & 61,94 \\
\hline 14 títulos diferentes & 14 & 1,23 & 112 & 9,90 & 8 & 112 & 2,21 & 3251 & 64,15 \\
\hline 20 títulos diferentes & 20 & 1,76 & 132 & 11,67 & 7 & 140 & 2,76 & 3391 & 66,91 \\
\hline SUBTOTAL & & 10,20 & & & & & 33,64 & & \\
\hline 25 titulos diferentes & 25 & 2,20 & 157 & 13,88 & 6 & 150 & 2,96 & 3541 & 69,87 \\
\hline 29 títulos diferentes & 29 & 2,55 & 186 & 16,45 & 5 & 145 & 2,86 & 3686 & 72,73 \\
\hline 39 títulos diferentes & 39 & 3,44 & 225 & 19,89 & 4 & 156 & 3,08 & 3842 & 75,81 \\
\hline 77 títulos diferentes & 77 & 6,80 & 302 & 26,70 & 3 & 231 & 4,56 & 4073 & 80,37 \\
\hline 166 títulos diferentes & 166 & 14,67 & 468 & 41,38 & 2 & 332 & 6,55 & 4405 & 86,92 \\
\hline 663 titulos diferentes & 663 & 58,61 & 1131 & 100 & 1 & 663 & 13,08 & 5068 & 100,00 \\
\hline SUBTOTAL & & 88,27 & & & & & 33,09 & & \\
\hline TOTAL & 1.131 & 100 & & & 2.325 & 5.068 & 100 & & \\
\hline
\end{tabular}

Fonte: Elaborada pelos autores

\footnotetext{
${ }^{2}$ Apresentam-se como "títulos diferentes" periódicos desiguais que receberam a mesma frequência de citação. No caso específico, Exame e Journal of Retailing receberam 39 citações cada um.
} 
TABELA 3

Títulos dos periódicos citados nas teses defendidas na área de contabilidade e finanças

\begin{tabular}{|c|c|c|c|c|c|}
\hline TÍTULO & $\begin{array}{c}\text { TÍTULOS } \\
\text { ACUMULADOS }\end{array}$ & $(\%)$ & $\begin{array}{c}\text { FREQ. } \\
\text { DE CITAÇÃO }\end{array}$ & $\begin{array}{c}\text { CITAÇÕES } \\
\text { ACUMULADAS }\end{array}$ & $(\%)$ \\
\hline Journal of Finance & 1 & 1,82 & 25 & 25 & 14,20 \\
\hline Journal of Financial Economics & 2 & 3,64 & 21 & 46 & 26,14 \\
\hline Working Paper Social Science Research Network & 3 & 5,45 & 15 & 61 & 34,66 \\
\hline American Economic Review & 4 & 7,27 & 12 & 73 & 41,48 \\
\hline Quarterly Journal of Economics & 5 & 9,09 & 11 & 84 & 47,73 \\
\hline Revista de Administração & 6 & 10,91 & 9 & 93 & 52,84 \\
\hline Journal of Political Economy & 7 & 12,73 & 6 & 99 & 56,25 \\
\hline Journal of Applied Corporate Finance & 8 & 14,55 & 5 & 104 & 59,09 \\
\hline 4 títulos diferentes & 12 & 21,82 & 4 & 120 & 68,18 \\
\hline 2 títulos diferentes & 14 & 25,45 & 3 & 126 & 71,59 \\
\hline 9 títulos diferentes & 23 & 41,82 & 2 & 144 & 81,82 \\
\hline 32 títulos diferentes & 55 & 100 & 1 & 176 & 100 \\
\hline TOTAL & 55 & & & 176 & \\
\hline
\end{tabular}

Fonte: Elaborada pelos autores

TABELA 4

Títulos dos periódicos citados nas teses defendidas na área de gestão da tecnologia e da produção

\begin{tabular}{|c|c|c|c|c|c|}
\hline TÍTULO & $\begin{array}{c}\text { TÍTULOS } \\
\text { ACUMULADOS }\end{array}$ & $(\%)$ & $\begin{array}{c}\text { FREQ. } \\
\text { DE CITAÇÃO }\end{array}$ & $\begin{array}{c}\text { CITAÇÕES } \\
\text { ACUMULADAS }\end{array}$ & $(\%)$ \\
\hline Strategic Management Journal & 1 & 0,29 & 72 & 72 & 6,29 \\
\hline Administrative Science Quarterly & 2 & 0,59 & 50 & 122 & 10,66 \\
\hline Harvard Business Review & 3 & 0,88 & 48 & 170 & 14,85 \\
\hline Academy of Management Review & 4 & 1,18 & 47 & 217 & 18,95 \\
\hline Research Policy & 5 & 1,47 & 32 & 249 & 21,75 \\
\hline Organization Studies & 6 & 1,77 & 31 & 280 & 24,45 \\
\hline Revista de Administração de Empresas & 7 & 2,06 & 27 & 307 & 26,81 \\
\hline California Management Review & 8 & 2,36 & 22 & 329 & 28,73 \\
\hline Academy of Management Journal & 9 & 2,65 & 21 & 350 & 30,57 \\
\hline Revista de Administração da USP & 10 & 2,95 & 19 & 369 & 32,23 \\
\hline ReD Management & 11 & 3,24 & 18 & 387 & 33,80 \\
\hline 2 títulos diferentes & 13 & 3,83 & 17 & 421 & 36,77 \\
\hline 4 títulos diferentes & 17 & 5,01 & 16 & 485 & 42,36 \\
\hline 2 títulos diferentes & 19 & 5,60 & 14 & 513 & 44,80 \\
\hline 2 títulos diferentes & 21 & 6,19 & 11 & 535 & 46,72 \\
\hline 3 títulos diferentes & 24 & 7,08 & 10 & 565 & 49,34 \\
\hline 5 títulos diferentes & 29 & 8,55 & 9 & 610 & 53,28 \\
\hline 5 títulos diferentes & 34 & 10,03 & 8 & 650 & 56,77 \\
\hline 5 títulos diferentes & 39 & 11,50 & 6 & 680 & 59,39 \\
\hline 8 títulos diferentes & 47 & 13,86 & 5 & 720 & 62,88 \\
\hline 11 títulos diferentes & 58 & 17,11 & 4 & 764 & 66,72 \\
\hline 28 títulos diferentes & 86 & 25,37 & 3 & 848 & 74,06 \\
\hline 44 títulos diferentes & 130 & 38,35 & 2 & 936 & 81,75 \\
\hline 209 títulos diferentes & 339 & 100 & 1 & 1145 & 100 \\
\hline TOTAL & 339 & & & 1.145 & \\
\hline
\end{tabular}

Fonte: Elaborada pelos autores 
Periódicos eletrônicos sobre administração disponíveis no portal de periódicos da Coordenação de Aperfeiçoamento de Pessoal...

TABELA 5

Títulos dos periódicos citados nas teses defendidas na área de marketing

\begin{tabular}{|c|c|c|c|c|c|}
\hline TÍTULO & $\begin{array}{c}\text { TÍTULOS } \\
\text { ACUMULADOS }\end{array}$ & $(\%)$ & $\begin{array}{l}\text { FREQ. } \\
\text { DE CITAÇÃO }\end{array}$ & $\begin{array}{c}\text { CITAÇÕES } \\
\text { ACUMULADAS }\end{array}$ & $(\%)$ \\
\hline Journal of Marketing & 1 & 0,30 & 300 & 300 & 18,82 \\
\hline Journal of Marketing Research & 2 & 0,61 & 120 & 420 & 26,35 \\
\hline Journal of the Academy of Marketing Science & 3 & 0,91 & 76 & 496 & 31,12 \\
\hline Journal of Consumer Research & 4 & 1,22 & 41 & 537 & 33,69 \\
\hline Harvard Business Review & 5 & 1,52 & 34 & 571 & 35,82 \\
\hline Journal of Retailing & 6 & 1,83 & 31 & 602 & 37,77 \\
\hline International Journal of Research in Marketing & 7 & 2,13 & 30 & 632 & 39,65 \\
\hline Journal of Services Marketing & 8 & 2,44 & 29 & 661 & 41,47 \\
\hline Journal of Market-Focused Management & 9 & 2,74 & 28 & 689 & 43,22 \\
\hline Academy of Management Review & 10 & 3,05 & 25 & 714 & 44,79 \\
\hline Psychological Bulletin & 11 & 3,35 & 24 & 738 & 46,30 \\
\hline 2 títulos diferentes & 13 & 3,96 & 23 & 784 & 49,18 \\
\hline Administrative Science Quarterly & 14 & 4,27 & 19 & 803 & 50,38 \\
\hline Marketing Science & 15 & 4,57 & 16 & 819 & 51,38 \\
\hline 3 títulos diferentes & 18 & 5,49 & 15 & 864 & 54,20 \\
\hline Journal of Marketing Theory and Practice & 19 & 5,79 & 14 & 878 & 55,08 \\
\hline Service Industries Journal & 20 & 6,10 & 13 & 891 & 55,90 \\
\hline 2 títulos diferentes & 22 & 6,71 & 12 & 915 & 57,40 \\
\hline 5 títulos diferentes & 27 & 8,23 & 11 & 970 & 60,85 \\
\hline 2 títulos diferentes & 29 & 8,84 & 10 & 990 & 62,11 \\
\hline 3 titulos diferentes & 32 & 9,76 & 9 & 1.017 & 63,80 \\
\hline 8 títulos diferentes & 40 & 12,20 & 8 & 1.081 & 67,82 \\
\hline 3 títulos diferentes & 43 & 13,11 & 7 & 1.102 & 69,13 \\
\hline 4 títulos diferentes & 47 & 14,33 & 6 & 1.126 & 70,64 \\
\hline 9 títulos diferentes & 56 & 17,07 & 5 & 1.171 & 73,46 \\
\hline 15 títulos diferentes & 71 & 21,65 & 4 & 1.231 & 77,23 \\
\hline 26 títulos diferentes & 97 & 29,57 & 3 & 1.309 & 82,12 \\
\hline 54 títulos diferentes & 151 & 46,04 & 2 & 1.417 & 88,90 \\
\hline 177 títulos diferentes & 328 & 100 & 1 & 1.594 & 100 \\
\hline TOTAL & 328 & & & 1.594 & \\
\hline
\end{tabular}

Fonte: Elaborado pelos autores

TABELA 6

Títulos dos periódicos citados nas teses defendidas na área de recursos humanos

\begin{tabular}{|c|c|c|c|c|c|}
\hline TÍTULO & $\begin{array}{c}\text { TÍTULOS } \\
\text { ACUMULADOS }\end{array}$ & $(\%)$ & $\begin{array}{c}\text { FREQ. } \\
\text { DE CITAÇÃO }\end{array}$ & $\begin{array}{c}\text { CITAÇÕES } \\
\text { ACUMULADAS }\end{array}$ & $(\%)$ \\
\hline Academy of Management Revien & 1 & 0,43 & 28 & 28 & 4,72 \\
\hline Harvard Business Revien & 2 & 0,86 & 25 & 53 & 8,94 \\
\hline Revista de Administrafão de Empresas & 3 & 1,29 & 22 & 75 & 12,65 \\
\hline Management Learning & 4 & 1,72 & 19 & 94 & 15,85 \\
\hline Human Relations & 5 & 2,15 & 16 & 110 & 18,55 \\
\hline Organization Science & 6 & 2,58 & 14 & 124 & 20,91 \\
\hline Revista Brasileira de Savide Ocupacional & 7 & 3,00 & 14 & 138 & 23,27 \\
\hline Administrative Science Quarterly & 8 & 3,43 & 12 & 150 & 25,30 \\
\hline Journal of European Industrial Training & 9 & 3,86 & 12 & 162 & 27,32 \\
\hline Revista de Administrafão da USP & 10 & 4,29 & 12 & 174 & 29,34 \\
\hline Journal of Management Development & 11 & 4,72 & 11 & 185 & 31,20 \\
\hline Sloan Management Review & 12 & 5,15 & 11 & 196 & 33,05 \\
\hline 4 títulos diferentes & 16 & 6,87 & 9 & 232 & 39,12 \\
\hline 3 títulos diferentes & 19 & 8,15 & 8 & 256 & 43,17 \\
\hline 2 títulos diferentes & 21 & 9,01 & 7 & 270 & 45,53 \\
\hline International Journal of Organizational Analysis & 22 & 9,44 & 6 & 276 & 46,54 \\
\hline 4 títulos diferentes & 26 & 11,16 & 5 & 296 & 49,92 \\
\hline 5 títulos diferentes & 31 & 13,30 & 4 & 316 & 53,29 \\
\hline 21 títulos diferentes & 52 & 22,32 & 3 & 379 & 63,91 \\
\hline 33 títulos diferentes & 85 & 36,48 & 2 & 445 & 75,04 \\
\hline 148 títulos diferentes & 233 & 100 & 1 & 593 & 100 \\
\hline TOTAL & 233 & & & 593 & \\
\hline
\end{tabular}

Fonte: Elaborada pelos autores 
TABELA 7

Títulos dos periódicos citados nas teses defendidas na área de organizações

\begin{tabular}{|c|c|c|c|c|c|}
\hline TÍTULO & $\begin{array}{c}\text { TÍTULOS } \\
\text { ACUMULADOS }\end{array}$ & $(\%)$ & $\begin{array}{c}\text { FREQ. } \\
\text { DE CITAÇÃO }\end{array}$ & $\begin{array}{c}\text { CITAÇÕES } \\
\text { ACUMULADAS }\end{array}$ & $(\%)$ \\
\hline Acadeny of Management Review & 1 & 0,42 & 27 & 27 & 4,75 \\
\hline Administrative Science Quarterly & 2 & 0,85 & 25 & 52 & 9,15 \\
\hline Saúde em Debate & 3 & 1,27 & 22 & 74 & 13,03 \\
\hline Revista de Administração de Empresas & 4 & 1,69 & 21 & 95 & 16,73 \\
\hline Strategic Management Journal & 5 & 2,12 & 19 & 114 & 20,07 \\
\hline Revista de Administração Pública & 6 & 2,54 & 16 & 130 & 22,89 \\
\hline Harvard Business Review & 7 & 2,97 & 15 & 145 & 25,53 \\
\hline California Management Revien & 8 & 3,39 & 12 & 157 & 27,64 \\
\hline Journal of Applied Psychology & 9 & 3,81 & 12 & 169 & 29,75 \\
\hline Ciência e Savide Coletiva & 10 & 4,24 & 9 & 178 & 31,34 \\
\hline Organization Studies & 11 & 4,66 & 8 & 186 & 32,75 \\
\hline 7 títulos diferentes & 18 & 7,63 & 7 & 235 & 41,37 \\
\hline 3 títulos diferentes & 21 & 8,90 & 6 & 253 & 44,54 \\
\hline 6 títulos diferentes & 27 & 11,44 & 5 & 283 & 49,82 \\
\hline 6 títulos diferentes & 33 & 13,98 & 4 & 307 & 54,05 \\
\hline 17 títulos diferentes & 50 & 21,19 & 3 & 358 & 63,03 \\
\hline 24 títulos diferentes & 74 & 31,36 & 2 & 406 & 71,48 \\
\hline 162 títulos diferentes & 236 & 100 & 1 & 568 & 100 \\
\hline TOTAL & 236 & & & 568 & \\
\hline
\end{tabular}

Fonte: Elaborada pelos autores

TABELA 8

Títulos de periódicos citados nas teses da área de sistemas de informação e apoio à decisão

\begin{tabular}{|c|c|c|c|c|c|}
\hline TÍTULO & $\begin{array}{c}\text { TÍTULOS } \\
\text { ACUMULADOS }\end{array}$ & $(\%)$ & $\begin{array}{c}\text { FREQ. } \\
\text { DE CITAÇÃO }\end{array}$ & $\begin{array}{c}\text { CITAÇÕES } \\
\text { ACUMULADAS }\end{array}$ & $(\%)$ \\
\hline MIS Quarterly & 1 & 0,28 & 72 & 72 & 7,26 \\
\hline Harvard Business Review & 2 & 0,56 & 35 & 107 & 10,79 \\
\hline Management Science & 3 & 0,85 & 28 & 135 & 13,61 \\
\hline Journal of Management Information Systems & 4 & 1,13 & 26 & 161 & 16,23 \\
\hline Information Systems Research & 5 & 1,41 & 24 & 185 & 18,65 \\
\hline Sloan Management Review & 6 & 1,69 & 22 & 207 & 20,87 \\
\hline Journal of Finance & 7 & 1,98 & 21 & 228 & 22,98 \\
\hline Communications of the $A C M$ & 8 & 2,26 & 20 & 248 & 25,00 \\
\hline European Journal of Operational Research & 9 & 2,54 & 19 & 267 & 26,92 \\
\hline Information and Management & 10 & 2,82 & 18 & 285 & 28,73 \\
\hline Decision Sciences & 11 & 3,11 & 15 & 300 & 30,24 \\
\hline Decision Support Systems & 12 & 3,39 & 13 & 313 & 31,55 \\
\hline Journal of Financial Economics & 13 & 3,67 & 12 & 325 & 32,76 \\
\hline Journal of Global Information Management & 14 & 3,95 & 12 & 337 & 33,97 \\
\hline 3 títulos diferentes & 17 & 4,80 & 11 & 370 & 37,30 \\
\hline IBM Systems Journal & 18 & 5,08 & 10 & 380 & 38,31 \\
\hline 6 títulos diferentes & 24 & 6,78 & 9 & 434 & 43,75 \\
\hline 5 títulos diferentes & 29 & 8,19 & 8 & 474 & 47,78 \\
\hline 3 títulos diferentes & 32 & 9,04 & 7 & 495 & 49,90 \\
\hline 7 títulos diferentes & 39 & 11,02 & 6 & 537 & 54,13 \\
\hline 7 títulos diferentes & 46 & 12,99 & 5 & 572 & 57,66 \\
\hline 11 títulos diferentes & 57 & 16,10 & 4 & 616 & 62,10 \\
\hline 15 títulos diferentes & 72 & 20,34 & 3 & 661 & 66,63 \\
\hline 49 títulos diferentes & 121 & 34,18 & 2 & 759 & 76,51 \\
\hline 233 títulos diferentes & 354 & 100 & 1 & 992 & 100 \\
\hline TOTAL & 354 & & & 992 & \\
\hline
\end{tabular}

Fonte: Elaborada pelos autores 
Para determinar quais periódicos seriam avaliados no Portal Capes, colocou-se uma lupa sobre os títulos apurados na primeira zona do panorama geral (tabela 2), reunindo-os com os títulos das primeiras zonas apurados nas seis tabelas das áreas de concentração (tabelas 3 a 9), formando uma lista única com 72 títulos.

Após, procedeu-se à eliminação dos títulos que se encontravam repetidos, restando, assim, 40 títulos que constituem a coleção-núcleo, de acordo com os autores das teses estudadas: Academy of Management Journal; Academy of Management Review; Administrative Science Quarterly; Administrative Science Review; California Management Review; Ciência e Saúde Coletiva; Communications of the ACM; Decision Sciences; Decision Support Systems; European Journal of Operational Research; Harvard Business Review; Human Relations; Information and Management; Information Systems Research; Journal of Applied Psychology; Journal of Consumer Research; Journal of European Industrial Training; Journal of Finance; Journal of Financial Economics; Journal of Global Information Management; Journal of Management Development; Journal of Management Information Systems; Journal of Management Studies; Journal of Marketing; Journal of Marketing Research; Journal of the Academy of Marketing Science; Management Learning; Management Science; MIS Quarterly; Organization Science; R\&D Management; Research Policy; Revista Brasileira de Saúde Ocupacional; Revista de Administração da USP; Revista de Administração de Empresas; Revista de Administração Pública; Saúde em Debate; Sloan Management Review; Strategic Management Journal; e Working Paper Social Science Research Network.

A definição desta core collection viabiliza a avaliação dos periódicos eletrônicos sobre administração disponíveis no Portal de periódicos da Capes, principal fonte de informação técnica e científica das instituições de ensino superior no Brasil.

\section{AVALIAÇÃO}

Procedeu-se à consulta ao Portal para verificar a disponibilidade dos periódicos da amostra, bem como o período de sua cobertura. Verificou-se, também, a disponibilidade do título impresso na coleção de periódicos da UFRGS, consultando-se o SABi (quadro 1, a seguir).

Dez dos títulos de periódicos mais citados pelos doutorandos do PPGA encontraram-se como não disponíveis no Portal, representando $25 \%$ da amostra. Um é nacional, os demais são estrangeiros, destacando-se entre eles o periódico Administrative Science Review, citado por todas as áreas.

Dentre os dez títulos: para as áreas de gestão da tecnologia e da produção e recursos humanos, os doutorandos citam a Revista de Administração da USP; e para gestão da tecnologia e da produção e organizações, indicam o Strategic Management Journal, sinalizando a importância destes títulos não disponíveis para os pesquisadores.

Esta não disponibilidade representa, para a área de marketing, 50\% (2/4) dos títulos mais citados; significa cerca de $36 \%$ (4/11) dos títulos para a área de gestão da tecnologia e da produção; e cerca de $33 \%(1 / 3)$ para a área de contabilidade e finanças. As áreas de concentração menos afetadas com a não disponibilidade dos títulos mais citados são recursos humanos, com cerca de 16\% (2/12), organizações, com cerca de $9 \%(1 / 11)$ e sistemas de informação e apoio à decisão, com cerca de 7\% (1/14).

Dos 40 títulos da amostra, 30, ou 75\% (30/40) estão disponíveis no Portal, com alguns embargos.

Em oito dos títulos mais citados, ou $20 \%$ da amostra (8/40), há embargo do tipo "uma lacuna de tempo entre a última edição disponível e a última edição publicada”. Um título está disponível até 1999, três até 2000, um até 2001, um até 2002 e dois até 2003. Pode-se considerar que embargos entre onze e sete anos representam prejuízo significativo para as atividades de pesquisa dos doutorandos estudados, quanto ao acesso às informações importantes para a o desenvolvimento de suas teses. A área de gestão da tecnologia e da produção utilizou um título mais citado nesta situação. Marketing e recursos humanos têm, cada uma, dois títulos nesta condição, e três 
Ana Maria Mattos / Eduardo Wense Dias

QUADRO 1

Disponibilidade dos periódicos da amostra no Portal de Periódicos da Coordenação de Aperfeiçoamento de Pessoal de Nível Superior e no Sistema de Automação de Bibliotecas

\begin{tabular}{|c|c|c|c|c|c|c|}
\hline \multirow{2}{*}{ TítuLo } & \multirow{2}{*}{ ÁREA } & \multirow{2}{*}{ ISSN } & \multicolumn{2}{|c|}{ PORTAL CAPES } & \multicolumn{2}{|c|}{ OPAC UFRGS/SABi } \\
\hline & & & DISPONÍVEL? & PERÍODO & DISPONÍVEL? & PERÍODO \\
\hline Academy of Management Journal & GTP & $0001-4273$ & não & & $\operatorname{sim}$ & $\begin{array}{l}\text { 1960-1984; 1986-1998; } \\
\text { 2000-2001 e 2008 }\end{array}$ \\
\hline Academy of Management Review & RH & $0363-7425$ & não & & sim & $\begin{array}{c}\text { 1976-1984; 1989-2001; } \\
\text { 2008-2009 }\end{array}$ \\
\hline Administrative Science Quarterly & GTP & 0001-8392 & $\operatorname{sim}$ & $\begin{array}{c}1956- \\
\text { presente }\end{array}$ & $\operatorname{sim}$ & $\begin{array}{c}1956-1963 ; 1966 ; 1968 ; \\
1970-1976 ; 1979-1985 ; \\
1987-2001 ; 2003\end{array}$ \\
\hline Administrative Science Review & TODAS & $0001-8406$ & não & & não & \\
\hline California Management Review & GTP & $0008-1256$ & não & & $\operatorname{sim}$ & 1981--1983; 1993-1996 \\
\hline Ciência e Saúde Coletiva & ORG & $1413-8123$ & sim & $\begin{array}{l}1998 \text { - } \\
\text { presente }\end{array}$ & $\operatorname{sim}$ & 1996-2009 \\
\hline Communications of the ACM & SIAD & $1557-7317$ & $\operatorname{sim}$ & $\begin{array}{l}1958 \text { - } \\
\text { presente }\end{array}$ & $\operatorname{sim}$ & $1958-2005 ; 2009$ \\
\hline Decision Sciences & SIAD & $1540-5915$ & $\operatorname{sim}$ & $\begin{array}{l}1997- \\
\text { presente }\end{array}$ & não & \\
\hline Decision Support Systems & SIAD & $0167-9236$ & $\operatorname{sim}$ & $\begin{array}{c}1995- \\
\text { presente }\end{array}$ & não & \\
\hline $\begin{array}{l}\text { European Journal of Operational } \\
\text { Research }\end{array}$ & SIAD & $0377-2217$ & $\operatorname{sim}$ & $\begin{array}{l}1995- \\
\text { presente }\end{array}$ & não & \\
\hline Harvard Business Review & GTP & $0017-8012$ & $\operatorname{sim}$ & $1997-2000$ & $\operatorname{sim}$ & $\begin{array}{l}1955-1960 ; 1962-1963 ; \\
1965-1970 ; 1972-2005\end{array}$ \\
\hline Human Relations* & RH & $0018-7267$ & $\operatorname{sim}$ & \begin{tabular}{|c|}
$1997-1999$ \\
$1999-$ presente
\end{tabular} & $\operatorname{sim}$ & $1961-1963$ \\
\hline Information and Management & SIAD & $0378-7206$ & $\operatorname{sim}$ & $\begin{array}{c}1995- \\
\text { presente }\end{array}$ & $\operatorname{sim}$ & $1977-2003$ \\
\hline Information Systems Research & SIAD & $1526-5536$ & $\operatorname{sim}$ & $\begin{array}{l}2001- \\
\text { presente }\end{array}$ & $\operatorname{sim}$ & 1992; 1996-1999, 2002 \\
\hline Journal of Applied Psychology* & ORG & $0021-9010$ & $\operatorname{sim}$ & $\begin{array}{c}\begin{array}{c}1917- \\
\text { presente }\end{array} \\
1917-2008\end{array}$ & $\operatorname{sim}$ & $\begin{array}{l}1944-1969 ; 1971-1984 ; \\
1986-1991 ; 1996 ; 1999\end{array}$ \\
\hline Journal of Consumer Research & MKT & $1537-5277$ & não & & não & \\
\hline $\begin{array}{l}\text { Journal of European Industrial } \\
\text { Training }\end{array}$ & RH & 0309-0590 & $\operatorname{sim}$ & $\begin{array}{c}1994- \\
\text { presente }\end{array}$ & não & \\
\hline Journal of Finance* & $\mathrm{CF}$ & $1540-6261$ & $\operatorname{sim}$ & $\begin{array}{c}1998- \\
\text { presente }\end{array}$ & $\operatorname{sim}$ & $1962-2003$ \\
\hline Journal of Financial Economics & $\mathrm{CF}$ & $0304-405 \mathrm{X}$ & sim & $\begin{array}{c}1995- \\
\text { presente }\end{array}$ & não & \\
\hline $\begin{array}{l}\text { Journal of Global Information } \\
\text { Management }\end{array}$ & SIAD & 1533-7995 & não & & não & \\
\hline $\begin{array}{l}\text { Journal of Management } \\
\text { Development }\end{array}$ & RH & $0262-1711$ & $\operatorname{sim}$ & $\begin{array}{c}1994- \\
\text { presente }\end{array}$ & não & \\
\hline $\begin{array}{l}\text { Journal of Management } \\
\text { Information Systems }\end{array}$ & SIAD & $0742-1222$ & $\operatorname{sim}$ & $1999-2001$ & não & \\
\hline Journal of Management Studies & TODAS & $1467-6486$ & $\operatorname{sim}$ & $\begin{array}{l}1997 \text { - } \\
\text { presente }\end{array}$ & $\operatorname{sim}$ & $\begin{array}{c}\text { 1991-1992; 1996-1998; } \\
2000\end{array}$ \\
\hline Journal of Marketing & MKT & $0022-2429$ & $\operatorname{sim}$ & 2003 & $\operatorname{sim}$ & $\begin{array}{c}1961 ; 1963-1985 \\
1987-2001\end{array}$ \\
\hline Journal of Marketing Research & MKT & $0022-2437$ & sim & 2003 & $\operatorname{sim}$ & $\begin{array}{l}1965 ; 1967-1985 \\
\text { 1987-2001 }\end{array}$ \\
\hline $\begin{array}{l}\text { Journal of the Academy of } \\
\text { Marketing Science }\end{array}$ & MKT & $1552-7824$ & não & & não & \\
\hline Management Learning & $\mathrm{RH}$ & $1461-7307$ & $\operatorname{sim}$ & $\begin{array}{c}1999 \text { - } \\
\text { presente }\end{array}$ & não & \\
\hline Management Science & SIAD & $1526-5501$ & $\operatorname{sim}$ & $\begin{array}{l}2001- \\
\text { presente }\end{array}$ & $\operatorname{sim}$ & $\begin{array}{c}1960-1967 ; 1969 ; \\
1972-1984 ; 1986-2000 ; \\
2002\end{array}$ \\
\hline MIS Quarterly & SIAD & $0276-7783$ & $\operatorname{sim}$ & $1995-2002$ & $\operatorname{sim}$ & $\begin{array}{l}\text { 1987; 1989-1998; } \\
\text { 2001-2003 }\end{array}$ \\
\hline Organization Science & RH & $1526-5455$ & $\operatorname{sim}$ & $\begin{array}{c}2001- \\
\text { presente }\end{array}$ & $\operatorname{sim}$ & $1992 ; 1995-1998 ; 2002$ \\
\hline$R \& D$ Management & GTP & $1467-9310$ & sim & $\begin{array}{l}1997 \text { - } \\
\text { presente }\end{array}$ & não & \\
\hline
\end{tabular}


Periódicos eletrônicos sobre administração disponíveis no portal de periódicos da Coordenação de Aperfeiçoamento de Pessoal...

\section{QUADRO 1 - Conclusão}

\begin{tabular}{|c|c|c|c|c|c|c|}
\hline \multirow{2}{*}{ TÍTULO } & \multirow{2}{*}{ ÁREA } & \multirow{2}{*}{ ISSN } & \multicolumn{2}{|c|}{ PORTAL CAPES } & \multicolumn{2}{|c|}{ OPAC UFRGS/SABi } \\
\hline & & & DISPONIVEL? & PERÍODO & DISPONÍVEL? & PERÍODO \\
\hline Research Policy & GTP & $0048-7333$ & $\operatorname{sim}$ & $\begin{array}{c}1995- \\
\text { presente }\end{array}$ & $\operatorname{sim}$ & $1986-1987 ; 1993-1994$ \\
\hline $\begin{array}{l}\text { Revista Brasileira de Saúde } \\
\text { Ocupacional }\end{array}$ & RH & 0303-7657 & $\operatorname{sim}$ & $\begin{array}{c}2004- \\
\text { presente }\end{array}$ & $\operatorname{sim}$ & $1973-1997 ; 2006-2009$ \\
\hline Revista de Administração da USP & GTP/RH & $0080-2107$ & não & & $\operatorname{sim}$ & $\begin{array}{l}1947-1949 ; 1951-1953 ; \\
1962 ; 1965 ; 1977-2008\end{array}$ \\
\hline $\begin{array}{l}\text { Revista de Administração de } \\
\text { Empresas }\end{array}$ & $\begin{array}{c}\text { GTP/RH/OR } \\
\text { G }\end{array}$ & $0034-7590$ & $\operatorname{sim}$ & $\begin{array}{c}1961- \\
\text { presente }\end{array}$ & $\operatorname{sim}$ & 1961-2009 \\
\hline Revista de Administração Pública & ORG & $0034-7612$ & $\operatorname{sim}$ & $\begin{array}{c}2006- \\
\text { presente }\end{array}$ & $\operatorname{sim}$ & $1967-2009$ \\
\hline Saúde em Debate & ORG & 0103-1104 & $\operatorname{sim}$ & $\begin{array}{c}\text { 1999- } \\
\text { presente }\end{array}$ & $\operatorname{sim}$ & $\begin{array}{c}\text { 1976-1978; 1980-1996; } \\
1999-2005 ; 2009\end{array}$ \\
\hline Sloan Management Review & RH/SIAD & 0019-848X & $\operatorname{sim}$ & $1995-2000$ & $\operatorname{sim}$ & $1981-1987 ; 1989-2000$ \\
\hline Strategic Management Journal & GTP/ORG & $1097-0266$ & não & & $\operatorname{sim}$ & $\begin{array}{c}\text { 1981-1984; 1988-1999; } \\
2002\end{array}$ \\
\hline $\begin{array}{l}\text { Working Paper Social Science } \\
\text { Research Network }\end{array}$ & $\mathrm{CF}$ & & não & & não & \\
\hline
\end{tabular}

Fonte: Portal de Periódicos da Coordenação de Aperfeiçoamento de Pessoal de Nível Superior e Sistema de Automação de Bibliotecas em 26 de maio de 2009.

Nota: Os títulos sinalizados com * são fornecidos por duas editoras.

dos títulos mais citados pela área de sistemas de informação e apoio à decisão, também.

Quanto ao embargo do tipo "não cobertura retrospectiva da assinatura dos títulos, promovendo falhas que não são cobertas pela coleção física da biblioteca" observaram-se seis títulos: da revista Human Relations, o Portal oferece o período entre 1997 até o presente, e a coleção UFRGS possui a versão impressa de 1961 até 1963. Do periódico Information Systems Research, o Portal oferece o período entre 2001 até o presente, e a coleção UFRGS possui a versão impressa de 1992, 1996 até 1999 e 2002. Das revistas Journal of Marketing e Journal of Marketing Research, o Portal oferece o ano de 2003, e a coleção UFRGS possui a versão impressa de 1961, 1963 até 1985 e 1987 até 2001. Do título Organization Science, o Portal oferece o período entre 2001 até o presente, e a coleção UFRGS possui a versão impressa de 1992, 1995 até 1998 e 2002. E, por fim, do periódico Revista Brasileira de Saúde Ocupacional, o Portal oferece o período entre 2004 até o presente, e a coleção UFRGS possui a versão impressa de 1973 até 1997 e 2006 até 2009.

As áreas mais prejudicadas por este tipo de embargo são: marketing, com duas revistas, ou 50\% (2/4) e recursos humanos, com três revistas, ou 25\% (3/12). Destaca-se que as revistas Journal of Marketing e Journal of Marketing Research apresentam dois tipos de embargo: tanto ocorre "uma lacuna de tempo entre a última edição disponível e a última edição publicada", quanto ocorre a "não cobertura retrospectiva da assinatura dos títulos, promovendo falhas que não são cobertas pela coleção física da biblioteca". Considera-se esta situação preocupante, dado que a frequência de citação dos periódicos é alta: 325 e 150, respectivamente. Destacase que o Journal of Marketing é o periódico mais citado pelos alunos pesquisados.

Foram encontrados, assim, 15\% (6/40) dos títulos com este tipo de embargo, ou seja, com hiatos na coleção dos periódicos mais citados nas teses estudadas. Captou-se um gap de 32 anos para um título; para outro, seis anos; outro título com dois anos; por fim, três com um ano de gap.

Resumindo-se a análise até o momento, dos 40 títulos da core collection, dez não estão disponíveis no Portal, oito apresentam uma lacuna entre a coleção física de periódicos da UFRGS e a disponibilidade do periódico no Portal, e seis não se acham disponíveis até o presente.

Dos títulos estudados, $60 \%$ (24/40) se encontram descritos no Portal com disponibilidade até o presente, incluindo-se aqui o embargo do tipo gap na coleção. Procedeu-se então à consulta de cada 
título com o intuito de verificar a disponibilidade do texto completo no Portal, ou a ocorrência da terceira forma de embargo definida como "acesso apenas aos resumos (abstracts) dos artigos". Verificou-se que todos os títulos se encontravam disponíveis com acesso ao texto completo.

Os 24 títulos mais citados pelos alunos estudados e com acesso até o presente no Portal Capes distribuem-se da seguinte forma entre as áreas de concentração: para contabilidade e finanças, dois títulos ou cerca de 66\% (2/3); para gestão da tecnologia e da produção, três títulos ou cerca de 27\% (3/11); para Organizações, quatro títulos disponíveis ou cerca de 36\% (4/11); para recursos humanos, seis títulos ou 50\% (6/12); e para sistemas de informação e apoio à decisão, sete títulos disponíveis ou 50\% (7/14). O mais grave ocorreu com os títulos mais citados na área de marketing: 100\% (4/4) dos títulos mais citados não se encontram disponíveis até o presente.

O Journal of Management Studies foi utilizado por todas as áreas, e a Revista de Administração de Empresas foi utilizada por três áreas: gestão da tecnologia e da produção, recursos humanos e organizações.

Entretanto, nove títulos, ou 22,5\% (9/40) da amostra, que não se encontravam disponíveis na coleção de periódicos em papel da UFRGS, foram os mais citados nas áreas de contabilidade e finanças (1), gestão da tecnologia e da produção (1), recursos humanos (3) e sistemas de informação e apoio à decisão (4), mas se encontram disponíveis no Portal até o presente, exceção do Journal of Management Information Systems, disponível até 2001.

Constata-se assim que, em algumas áreas, os novos títulos de periódicos disponíveis no Portal têm sido efetivamente consultados e utilizados pelos autores das teses estudadas em suas pesquisas. Contudo, para os autores das áreas de organizações e marketing, não foi observado fato semelhante. Tal fenômeno já havia sido reportado por Soares (2004, p. 11, grifo do autor):

Cursos que, há cinco anos, eram infactíveis nos programas de ponta do país por falta de acesso à bibliografia, passaram a poder ser oferecidos em todas as instituições vinculadas ao Portal Capes. O teto para o embasamento empírico, teórico e comparativo de muitas pesquisas foi multiplicado. Universidades, departamentos, centros de pesquisa, programas de pós-graduação e pesquisadores brasileiros que, há menos de dez anos, não poderiam sonhar com ter acesso a dados e bibliografia atualizados na sua área, passaram a ter acesso a uma informação comparável à dos pesquisadores localizados em boas universidades de países ricos.

Ou seja, títulos até então desconhecidos, ou inacessíveis, que foram ofertados pelo Portal abrem novas possibilidades de ensino na pós-graduação. Como diz Soares (2004), o efeito do Portal Capes foi "equalizador". Entretanto, o autor faz uma ressalva muito importante quanto ao termo comparável destacado em seu texto:

Colocamos comparável em itálico porque ainda dista de ser igual. O acesso, pela Internet, a muitos periódicos se limita a anos recentes. $\mathrm{O}$ acesso, em grande medida, é a periódicos e não a livros, que são importantes, particularmente nas Ciências Sociais e nas Humanidades. Além disso, os serviços prestados pelas bibliotecas dependem do número e treinamento do pessoal. Já no início da década de 80, a Universidade de Yale empregava, na sua biblioteca, mais de 600 pessoas (SOARES, 2004, p. 11).

No caso deste estudo, um exemplo a ser destacado é o título Journal of Management Information System, que não se encontra disponível na coleção de periódicos em papel da UFRGS e, apesar de apresentar um embargo do tipo "uma lacuna de tempo entre a última edição disponível e a última edição publicada" no Portal Capes, encontra-se entre os periódicos mais citados pelos doutorandos.

\section{CONCLUSÃO}

Considera-se o avanço representado pelo acesso eletrônico de revistas científicas em todo o território brasileiro de grande relevância. Acredita-se que aqueles para os quais o Portal Capes se destina, usuários - pesquisadores e usuários bibliotecários -, têm muito a colaborar para seu aprimoramento. Resume-se assim o espírito desta investigação.

Ci. Inf., Brasília, DF, v. 39 n. 1, p.51-66, jan./abr., 2010 
Periódicos eletrônicos sobre administração disponíveis no portal de periódicos da Coordenação de Aperfeiçoamento de Pessoal...

Contudo, para os usuários estudados, somando-se os títulos de periódicos mais citados nas teses e que se encontram como não disponíveis ou com algum tipo de embargo no Portal Capes, chegamos ao impressionante percentual de 60\% (24/40). Especificamente para a área de concentração de marketing do PPGA/EA/UFRGS, o acesso aos títulos de periódicos considerados mais importantes por eles pode ser julgado crítico, pois se apresentam como não disponíveis ou com um embargo de seis anos em relação ao ano corrente.

Pode-se destacar também que este efeito “equalizador" proporcionado pelo Portal (SOARES, 2004) tem seu lado negativo. Esta investigação demonstrou o quanto uma só disciplina pode apresentar peculiaridades, domínios e especificidades que precisam ser reconhecidos e caracterizados para atender a suas demandas informacionais. Em um país de dimensões continentais, com características regionais que repercutem nos interesses da pesquisa, tais demandas deveriam ser consideradas na aquisição dos materiais informacionais a serem disponibilizados no Portal. Quando os recursos do PAAP eram gerenciados em cada instituição superior de ensino e pesquisa isoladamente, recursos estes que foram redirecionados ao Portal, elas procuravam conhecer e atender às demandas informacionais de seus usuários.

Acredita-se que dados de acesso e uso (download) dos materiais informacionais disponíveis no Portal são de conhecimento da Capes. Às vésperas de completar a primeira década do Portal, torna-se necessária a mobilização das instituições de ensino e pesquisa que têm acesso a ele para que estudem seus usuários e conheçam suas demandas informacionais. O cruzamento destas informações pode representar economia de recursos financeiros, evitando as assinaturas complementares de periódicos não contemplados pelo Portal, assim como promover um salto de qualidade.

Artigo submetido em 26/08/2009 e aceito em 06/10/2010.

\section{REFERÊNCIAS}

ASSOCIAÇÃO BRASILEIRA DE NORMAS TÉCNICAS. NBR 6023: informação e documentação: referências: elaboração. Rio de Janeiro, 2002.

BRADFORD, S. C. Sources of information on specific subjects 1934. Journal of Information Science, Cambridge, USA, v. 10 , n. 4, p. 176-180, 1985. Disponivel em: <http://jis. sagepub.com/content/10/4/176.full.pdf + html>. Acesso em: 10 jun. 2009.

BRASIL. Ministério da Educação, Coordenação de Aperfeiçoamento de Pessoal de Nível Superior. Programa de apoio à aquisição de periódicos (PAAP). 2006. Disponível em: <http://www.capes.gov.br/servicos/informacaocientifica/2345-programa-de-apoio-a-aquisicao-de-periodicospaap>. Acesso em: 10 jun. 2009.

BRASIL. Ministério da Educação. Portal Periódicos (CAPES): o portal brasileiro da informação científica. 2009. Disponível em: <http://novo.periodicos.capes.gov.br/>. Acesso em: 27 set. 2010.

CENDÓN, B. V. Serviços de indexação e resumo. In: CAMPELLO, B. S.; CENDÓN, B. V.; KREMER, J. M. (Orgs.). Fontes de informação para pesquisadores e profissionais. Belo Horizonte: Editora UFMG, 2000. p. 217-248.

CORREA, C. H. W. et al. Portal de Periódicos da CAPES: um misto de solução financeira e inovação. Revista Brasileira de Inovação, Rio de Janeiro, v. 7, n. 1, p.127-145, jan./jun. 2008. Disponível em: < http://www.finep.gov.br/revista_brasileira inovacao/decima_terceira_edicao/04_Portal_Periódicos_ CAPES.pdf>. Acesso em: 26 maio 2009.

CRUZ, A. A. A. C. da et al. Impacto dos periódicos eletrônicos em bibliotecas universitárias. Ciência da Informação, Brasília, v. 32, n. 2, maio/ago. 2003, p. 47-53. Disponível em: <http:// www.scielo.br/pdf/\%0D/ci/v32n2/17032.pdf > . Acesso em 26 maio 2009.

DUTRA, S. K. W.; LAPOLLI, E. M. Portal de periódicos da CAPES: análise do uso na Universidade Federal de Santa Catarina. In: SEMINÁRIO NACIONAL DE BIBLIOTECAS UNIVERSITÁRIAS, 13., 2004, Natal. Anais... Natal: UFRN, 2004. 1 CD-ROM.

FRAGA, T. M. A.; MATTOS, A. M. Periódicos eletrônicos sobre Administração no Portal Capes: algumas reflexões. In: CONFERÊNCIA IBERO-AMERICANA DE PUBLICAÇÕES ELETRÔNICAS NO CONTEXTO DA COMUNICAÇÃO, 2., 2008, Rio de Janeiro. Anais... Brasília, DF: IBICT, 2008. Disponível em: <http://cipecc2008. ibict.br/index.php/CIPECC2008/cipecc2008/paper/ viewFile/26/69>. Acesso em 27 set. 2010. 
GARFIELD, E. Is citation frequency a valid criterion for selecting journals? Essays of an Information Scientist, Philadelphia, v. 1, p. 289-290, 1977. Disponível em: <http://www.garfield. library.upenn.edu/essays/V1p289y1962-73.pdf > . Acesso em: 26 maio 2009.

KOVACS, B. Decision making in collection development literature. In: The decision-making process for library collections: case studies in four types of libraries. New York: Greenwood, 1990. p. 13-22. (Contributions in librarianship and information science, 65).

KURAMOTO, H. Informação científica: proposta de um novo modelo para o Brasil. Ciência da Informação, Brasília, v. 35, n. 2, p. 91-102, maio/ago. 2006. Disponível em: < http://www.scielo. br/pdf/ci/v35n2/a10v35n2.pdf>. Acesso em: 27 set. 2010.

LEMOS, B. Periódicos Eletrônicos: problema ou solução? DataGramaZero: Revista de Ciência da Informação on-line, v. 7, n. 3, jun. 2006. Disponível em: < http://www.dgz.org.br/ jun06/Ind_com.htm>. Acesso em: 16 ago 2008.

LINE, M. B. Rank lists based on citations and library uses as indicators of journal usage in individual libraries. Collection Management: devoted to the management of library collections, New York, USA, v. 2, n. 4, p. 313-316, may, 1979.

MUELLER, S. P. M. O periódico científico. In: CAMPELLO, B. S.; CENDÓN, B. V.; KREMER, J. M. (Orgs.). Fontes de informação para pesquisadores e profissionais. Belo Horizonte: Editora UFMG, 2000. p. 73-96.
OKUBO, Y. Bibliometric indicators and analysis of research systems: methods and exemples. Paris: OECD Science, 1997. Disponível em: <http://www.oecd-ilibrary.org/docserver/ download $/$ fulltext $/ 5$ lgsjhvj7ng0.pdf?expires $=1285607082 \&$ $\mathrm{id}=0000 \&$ acc name $=$ guest $\&$ checksum $=4$ ABDEB025AA996 4F498A5B88789E5872>. Acesso em: 26 maio 2009.

SMITH, L. C. Citation analysis. Library Trends, Illinois, USA, v. 30, n. 1, p. 83-106, Summer 1981.

SOARES, G. A. D. O Portal de periódicos da Capes: dados e pensamentos. RBPG: revista brasileira de pós-graduação, v.1, n. 1, p. 10-25, jul. 2004. Disponível em: <http://www2. capes.gov.br/rbpg/images/stories/downloads/RBPG/ Vol.1_1_jul2004_/10_25_o_portal_de_periodicos.pdf $>$. Acesso em 05 maio 2009.

TARAPANOFF, K.; MIRANDA, D. M.; ARAÚJO JÚNIOR, R. H. de. (Colab.). Técnicas para tomada de decisão nos sistemas de informação. Brasília, DF: Thesaurus, 2004.

TUÑÓN, J.; BRYDGES, B. Improving the quality of university libraries through citation mining and analysis using two new dissertation bibliometric assessment tools. In: WORD LIBRARY AND INFORMATION CONGRESS. IFLA GENERAL CONFERENCE AND COUNCIL, 71., 2005, Oslo. Libraries: a voyage of discovery. Disponível em: < http:/ / www.ifla.org.sg/IV/ifla71/papers/078e-Tunon_Brydges. pdf $>$. Acesso em: 07 jun. 2006.

URBANO SALIDO, C. El análisis de citas en trabajos de investigadores como método para el estudio del uso de información en bibliotecas. Anales de Documentación, Murcia, v. 4, p. 243-266, 2001. Disponível em: <http://www.um.es/ $\mathrm{fccd} /$ anales/ad04/ad0400.html>. Acesso em: 17 jun. 2006. 